\title{
Construindo a docência na educação infantil: da observação à práxis
}

La construcción de la docencia en la educación infantil: de la observación a la praxis

Building teaching in early childhood education: from observation to practice

\author{
Lic. Lucas Martinez ${ }^{1}$ \\ Dra. Jane Pereira ${ }^{2}$
}

\begin{abstract}
Resumo
Este trabalho é resultado do período de prática docente na Educação Infantil, componente curricular do curso de Licenciatura em Pedagogia da Universidade Federal do Pampa, campus Jaguarão/RS. Neste sentido, tem como objetivo contextualizar como é possível construir temáticas significativas para o trabalho na prática docente na Educação Infantil, no âmbito do estágio, e consequentemente na prática profissional. A partir de uma concepção freireana de educação, buscou-se um tema central e quatro subtemas que emergem da realidade, pois pensar Paulo Freire na Educação Infantil é compreender que a educação é permanente vida, não apenas preparar para viver, mas educar na vida, ou seja, uma constante leitura do mundo, cada vez mais crítica.
\end{abstract}

Palavras-chave: Paulo Freire; Educação Infantil; Estágio.

\section{Resumen}

Este trabajo es resultado del período de práctica docente en la Educación Infantil, componente curricular del curso de Licenciatura en Pedagogía de la Universidade Federal do Pampa, campus Jaguarão/RS. En este sentido, tiene como objetivo contextualizar cómo es posible construir temáticas significativas para el trabajo en la práctica docente en la Educación Infantil, en el ámbito del estágio, y consecuentemente en la práctica profesional. A partir de una concepción Freireana de educación, se buscó un tema central y cuatro subtemas que emergen de la realidad, pues pensar Paulo Freire en la Educación Infantil es comprender que la educación es permanente en la vida, no apenas preparar para vivir, mas educar en la vida, o sea, una constante lectura del mundo, cada vez más crítica.

Palabras-clave: Paulo Freire. Educación Infantil; Estágio.

\begin{abstract}
This work is the result of teaching practice period in early childhood education, curriculum component of the Bachelor's Degree in Education from the Federal University of Pampa, campus Jaguarão/RS . In this sense, the main objective of this study is to contextualize how you can build meaningful themes to work on teaching practice in kindergarten under the stage but also in the context of professional practice. From a Freire's concept of education, what is proposed is to find themes that emerge from the reality, because think of Paulo Freire in early childhood education is to understand that education is permanent life, not just preparing to live, but to educate in life, in a continuous reading of the world, more and more critical .
\end{abstract}

Keywords: Paulo Freire ; Childhood education; Stage.

\footnotetext{
1 Licenciado em Pedagogia e mestrando em Educação, Universidade Federal de Santa Maria - Brasil, lukasspedagogia@gmail.com.
}

${ }^{2}$ Doutora em Educação, Universidade Federal do Pampa - Brasil, mixjanepereira@yahoo.com.br. 


\section{Introdução}

Este trabalho foi realizado, no período de prática docente na Educação Infantil, componente curricular do curso de Licenciatura em Pedagogia da Universidade Federal do Pampa, campus Jaguarão, no segundo semestre de 2015. Neste sentido, o objetivo principal é contextualizar como é possível construir temáticas significativas para o trabalho na prática docente na Educação Infantil e consequentemente, na prática profissional.

Tendo como embasamento a concepção freireana de educação, foi possível buscar temáticas que emergem da realidade, pois pensar Paulo Freire na Educação Infantil é compreender que a educação é permanente vida, não apenas preparar para viver, mas educar na vida, em uma constante leitura do mundo, cada vez mais crítica. Freire (1983) nos ajuda a pensar que o conhecimento a ser sistematizado deve passar pelas relações da vida e desta deve emergir. Contribuindo para essa discussão, podemos citar Charlot (2000) que afirma que os estudantes, sejam crianças, jovens e adultos estabelecem uma relação com o saber, pelo prazer, pela ligação com sua realidade local, pelas conexões afetivas, a relação do professor com o aluno, entre as práticas escolares e curriculares. Com base nisso, pensar a escola implica pensar práticas educativas que se relacionam efetivamente com a vida de seus estudantes. Construir-se sujeito implica problematizar e refletir sobre si, os outros, o mundo e a vida. Neste entendimento:

\footnotetext{
Quando se tira da criança a possibilidade de conhecer este ou aquele aspecto da realidade, na verdade se está alienando-a da sua capacidade de construir seu conhecimento. Porque o ato de conhecer é tão vital como comer ou dormir, e eu não posso comer ou dormir por alguém. A escola em geral tem esta prática, a de que o conhecimento pode ser doado, impedindo a criança e, também, os professores o construam. Só assim a busca pelo conhecimento não é preparação para nada, e sim VIDA, aqui e agora. E é esta vida que precisa ser resgatada pela escola. Muito temos que caminhar para isso, mas é no hoje que vamos viabilizando esse sonho de amanhã (FREIRE, 1983, p.15).
}

Neste contexto é pertinente afirmar que a metodologia utilizada no processo de emersão das temáticas, foi construída a partir do referencial teórico de Paulo Freire, Madalena Freire, entre outros. Também se embasa em documentos nacionais que subsidiam as discussões sobre a Educação Infantil.

Em linhas gerais contextualizo parte da experiência, com foco na observação e na constituição dos temas que embasou os planejamentos diários para a Educação Infantil. 


\section{O pensamento de Paulo Freire - discussões teóricas em busca de consenso}

Partindo do referencial teórico freireano, especificamente em sua Pedagogia do Oprimido (1983) a metodologia da investigação temática, a investigação do pensar e do falar do povo foi possível compreender as "palavras geradoras" na alfabetização e os "temas geradores" para o processo educativo dialógico mais amplo. Ainda hoje existem posturas que consideram que a obra de Paulo Freire serve apenas para refletir sobre a Educação Popular e para a Educação de Jovens e Adultos. O que Paulo Freire formula é uma epistemologia do conhecimento (ANDREOLA, 1993), onde o processo de aprender se dá através da curiosidade, no qual, em seu pensar, "O que importa é que professor e alunos se assumam epistemologicamente curiosos" (FREIRE, 1996).

Freire elabora diversas críticas pertinentes à educação e principalmente, às condições sociais do processo capitalista de sociedade, E a partir das dualidades opressor/oprimido, a relação entre educador e educando, educação "bancária" e educação problematizadora, as diferenças entre a construção de uma ação dialógica ou uma ação antidialógica e, considera que é preciso investigar o pensar do povo para criar propostas educativas apropriadas à estes sujeitos.

De acordo com Paulo Freire, a educação não pode ser bancária, apenas depositando conteúdos nos sujeitos, os tratando como objetos recipientes, prontos à serem preenchidos, mas justamente a educação precisa ser a da "problematização dos homens em suas relações como o mundo (FREIRE, 1983, p. 77).” Isso implica o diálogo, pois no pensamento freireano, o dialogo é a essência da educação como prática de liberdade. O diálogo é uma "exigência existencial (FREIRE, 1983, p.93)" e é através do dialogo que os homens se encontram, num processo de denúncia do mundo, para sua transformação. Assim, o diálogo, ou como está posto em sua pedagogia, a dialogicidade como essência de uma educação como prática de liberdade, é primordial.

Em Conscientização (1979) Freire traz umas das ideias-força de seu pensamento no qual consideramos importante ressaltar. Pensar esta ideia implica construir formas de aprimorar nossa prática e refinar nosso olhar mediante as questões de ensino e de currículo. Para ter validade, toda e qualquer educação, enquanto ação, ou planejamento precisa estar precedido de

[...] uma reflexão sobre o homem e de uma análise do meio de vida concreto do homem concreto a quem queremos educar (ou melhor, dito: a quem queremos ajudar a educar-se). 
Faltando uma reflexão sobre o homem, corre-se o risco de adotar métodos educativos e maneiras de atuar que reduzem o homem à condição de objeto (FREIRE 1979, p.34).

Portanto, considerando a importância de refletir sobre a realidade no qual nossos alunos existem, Freire instaura uma forma de investigar este pensar do povo. Dessa forma, considerando brevemente como é feito este processo para assim poder compreender como pensamos a estruturação de uma réplica no âmbito da prática do estágio e na Educação Infantil.

Para a primeira apreensão da realidade foram realizadas entrevistas, estabelecidos diálogos, buscando entender a visão das pessoas sobre sua realidade. Escutando sensivelmente as compreensões que as pessoas têm do mundo e de si. Todas estas impressões podem ser consideradas como "codificações ao vivo" (FREIRE, 1983). Codificações, em sua linguagem são situações existenciais na qual se considera importante problematizar.

Após este processo inicial, todas as impressões foram discutidas e "reduzidas tematicamente" pelos sujeitos do processo, em primeiro momentos professores, especialistas de diversas áreas (saúde, meio ambiente, entre outras), posteriormente os sujeitos que queremos ajudar a educarem-se, alunos crianças, jovens e adultos, ou pais. É importante lembrar que este processo foi pensado para um trabalho comunitário, em uma construção que é de base Educação Popular.

É importante ressaltar que a realidade só é obtida, de acordo com Freire (2006) a partir da objetividade e seu entrelaçamento com a subjetividade. Não é possível orientar uma pesquisa nessa perspectiva se ela, estudando o povo, o faz como objeto e não como sujeito.

Com o auxílio destes especialistas das diversas áreas do conhecimento, tais codificações são didatizadas, assim preparadas para o trabalho em salas de aulas, ou como Freire coloca (dentro da educação em espaços não escolares e populares): os Círculos de Cultura. Freire aponta que as codificações podem ser feitas de diversas formas: desde os materiais visuais, audiovisuais, até mesmo através de leituras, entre outras dinâmicas. Assim, o processo educativo na concepção freireana se daria a partir da dinâmica CODIFICAÇÃO PROBLEMATIZAÇÃO - DESCODIFICAÇÃO.

Em outras palavras, apresentar uma situação, problematizá-la, discuti-la à luz de diferentes áreas disciplinares e, aí a interdisciplinaridade é essencial e, assim criar uma nova visão daquela situação inicial. Um destes exemplos é a metodologia dos três momentos pedagógicos (DELIZOICOV; ANGOTTI, 1994), onde a prática é construída a partir de três momentos assim organizados: Problematização inicial, Organização do conhecimento e 
Aplicação do conhecimento. Esta metodologia tem potencial para ser trabalhada em várias situações educativas, mas, adaptada e re(elaborada) em diferentes áreas e na Educação Infantil.

Depois de feito este percurso, é preciso ter bom senso das limitações deste processo. As dinâmicas de construção deste processo se tornam bem limitadas, cabe que o currículo, sistematizado nos planos de estudos escolares possui certa rigorosidade e engessamento das práticas pedagógicas, então, esta investigação aponta para pensar ligações interdisciplinares entre os conhecimentos sistematizados nos planos de estudos e nos temas que são emergentes. A realidade da Educação Infantil é potencial neste sentido, pois até o presente momento trabalha-se a partir dos Referenciais Curriculares Nacionais para a Educação Infantil (BRASIL, 1998) em seus três volumes. Este fato proporciona um desdobramento maior das experiências de vida e de mundo que os sujeitos têm nas diferentes áreas de experiência que o referencial possui.

A partir disto, é possível estruturar temas significativos, compreendendo os limites e possibilidades da investigação temática freireana.

\section{Da observação à construção de temáticas}

O estágio supervisionado em Educação Infantil totalizado em 150 horas (20h para observação, $80 \mathrm{~h}$ de prática docente e $50 \mathrm{~h}$ de planejamento) requer a escrita de um memorial onde cada estagiário reflete sobre si e o caminho que fez na escola até chegar à universidade e um plano de trabalho, onde descreve e analisa teoricamente o período da observação na escola em que irá atuar até a delimitação de princípios orientadores, marcos referenciais, objetivos e temáticas, avaliação, entre outros. Como discutir isto tornaria demasiado extensivo, o foco se dá na construção da temática principal, distribuída entre "tema e subtemas" e como se estrutura, ou seja, o caminho percorrido até chegar neste tema.

No sentido de construir a prática pedagógica e seus referenciais, urge a necessidade de apontar "para o desenvolvimento do estágio como uma atitude investigativa, que envolve a reflexão e a intervenção na vida da escola, dos professores, dos alunos e da sociedade" (PIMENTA; LIMA, 2004, p. 34).

Porém, como a observação é a forma utilizada nesse contexto para compreender a realidade e buscar os temas, é necessário, entender melhor a observação. Albano Estrela (1992) ocupou-se ao estudo da observação como instrumento para a construção da pedagogia enquanto ciência. Quando falamos pedagogia não estamos falando sobre o curso de Licenciatura que forma professores para atuar na Educação Infantil, anos iniciais, entre outras. 
A Pedagogia enquanto ciência da educação é algo bastante discutido. Porém, objetivando a observação, é através dela que o professor se aproxima das questões pedagógicas.

Se um psicólogo analisa uma turma de Educação Infantil, por exemplo, ele utiliza bases da psicologia e produz uma reflexão psicológica. Se um sociólogo assim o fizer também estará utilizando bases da sociologia e estará construindo uma reflexão sociológica. Para Estrela (1992) a pedagogia não se libertou das diferentes ciências e não construiu um repertório de conhecimentos e ferramentas específicas referentes ao seu campo, o irredutível ou real pedagógico. Uma criança pode ser analisada por diferentes áreas, porém, no que se refere às práticas pedagógicas, o autor utiliza a observação como forma de compreender essa relação estabelecida entre o ensino e a aprendizagem. Dessa forma, na visão do referido autor, a observação é a ferramenta chave para a caracterização das situações pedagógicas com a finalidade de qualificar o processo pedagógico.

A prática na Educação Infantil precisa atender os seguintes princípios delimitados nas Diretrizes Curriculares Nacionais para a Educação Infantil - DCNEI (BRASIL, 2009), em seu artigo $n^{\circ} 6$ :

\footnotetext{
As propostas pedagógicas de Educação Infantil devem respeitar os seguintes princípios:

I- Éticos: da autonomia, da responsabilidade, da solidariedade e do respeito ao bem comum, ao meio ambiente e às diferentes culturas, identidades e singularidades. II- Políticos: dos direitos de cidadania, do exercício da criticidade e do respeito à ordem democrática.

III- Estéticos: da sensibilidade, da criatividade, da ludicidade e da liberdade de expressão nas diferentes manifestações artísticas e culturais.
}

O RCNEI traz como forma de estruturar o conhecimento na Educação Infantil aponta que a prática precisa compreender as seguintes experiências definidas assim: "Formação Pessoal e Social e Conhecimento de Mundo - que são constituídos pelos seguintes eixos de trabalho: Identidade e autonomia, Movimento, Artes visuais, Música, Linguagem oral e escrita, Natureza e sociedade, e Matemática" (BRASIL, 1998, p.43).

Dessa forma, embora não exista um plano de estudos que delimite conteúdos à serem trabalhados, o RCNEI traz categorias de experiências de mundo que devem ser privilegiadas.

O primeiro momento deste processo para construir a prática do estágio é a observação. As 20h de observação são necessárias para fazer os primeiros contatos com a escola, conhecer a escola, os profissionais, a rotina da sala de aula, seus diferentes espaços. Assim, a observação é realizada de diferentes formas, seja de forma mais neutra, seja de forma participante. Pela experiência obtida em outros momentos de formação e pela abertura e 
disponibilidade do professor titular, foi possível interagir em diferentes momentos mesmo que com cuidado para não interromper as práticas realizadas. É necessário compreender a natureza da observação, para não cair na concepção em que a observação

[...] reduz-se a observar os professores em aula e imitar esses modelos, sem
proceder a uma análise crítica fundamental teoricamente e legitimada na
realidade social em que o ensino se processa. Assim, a observação se limita à sala de
aula, sem análise do contexto escolar, e espera-se do estagiário a elaboração e
execução de "aulas-modelo" (PIMENTA; LIMA, 2004, p. 36).

Optamos em utilizar o registro das observações em formato de diário. $\mathrm{O}$ diário segundo Zabalza (2004, p. 24) pode tornar-se "o registro mais ou menos sistemático do que acontece nas nossas aulas" com a finalidade de nos dar "uma espécie de radiografia de nossa docência". Escrever sobre nós e nossa prática traz consigo a realização do processo de racionalizar as vivências, reconstruir e reviver a experiência e distanciar-se a ponto de poder analisar melhor (ZABALZA, 2004). O diário pode ser considerado uma ferramenta para o desenvolvimento profissional do professor (PORLÁN; MARTIN, 1997), pois se torna um instrumento de investigação de suas práticas.

Ali ele coloca muito mais do que atividades desenvolvidas, horários de entrada ou de saída, mas exprime suas impressões sobre o processo educativo, o que percebeu, o que sentiu, o que funcionou e o que não funcionou. Dessa forma, utilizar o diário no âmbito da observação e posteriormente na prática implica refletir sobre os diversos momentos educativos na escola, reações e ações que fundamentarão novos olhares e planejamentos. Neste sentido, a reflexão e a teorização das práticas é de suma importância, pois, "a prática pela prática e o emprego de técnicas sem a devida reflexão podem reforçar a ilusão de que há uma prática sem teoria ou de uma teoria desvinculada da prática" (PIMENTA; LIMA, 2004, p. 37).

O momento do estágio supervisionado torna-se um importante momento onde “aquisição e a construção de uma postura reflexiva pressupõe um exercício constante entre a utilização dos conhecimentos de natureza teórica e prática na ação e a elaboração de novos saberes, a partir da ação docente (BARREIRO; GEBRAN , 2006, p. 22)”. Pensar a prática no estágio implica compreender que "o estágio (...) é atividade teórica de conhecimento, fundamentação, diálogo e intervenção na realidade (...), ou seja, é no contexto da sala de aula, da escola, do sistema de ensino e da sociedade que a práxis se dá" (PIMENTA; LIMA, 2004, p. 45). 
A articulação da relação teoria e prática é um processo definidor da qualidade da formação inicial e continuada do professor, como sujeito autônomo na construção de sua profissionalização docente, porque lhe permite uma permanente investigação e a busca de respostas aos fenômenos e às contradições vivenciadas (BARREIRO; GEBRAN, 2006, p. 22).

Dentre os diferentes aspectos, falas, inferências subjetivas que foram possíveis imprimir, consideramos três situações potenciais a serem discutidas e aprofundadas. Tais situações foram intituladas em nossa perspectiva da seguinte forma: Situações Significativas Problematizadas. O item referente à observação no relatório foi estruturado descrevendo e analisando situações que, do nosso ponto de vista mereciam maior atenção.

As crianças se envolviam com música em diversos momentos durante as aulas, mas não existia nenhum planejamento que envolvesse cantar músicas, ensaiar músicas ou conhecê-las. As músicas geralmente quando apareciam na figura do professor, revelavam-se de forma controladora ou moralizante. A autora Maffioletti (2001) em relação à estas práticas musicais que buscam controlar e organizar o momento da atividade, aponta que:

A preocupação do professor é apenas de conter a turma, para que todos iniciem a refeição juntos, pois se ele prestasse atenção ao canto, certamente não suportaria tal execução. $\mathrm{Na}$ hora em que todos os alunos devem fazer algo juntos, a música aparece como uma forma de homogeneizar o tempo escolar: entrada, merenda e descanso. Este é um típico uso da música como recurso na educação, há tanto tempo criticado, mas incrivelmente vigente em todas as escolas. Estudos mais detalhados sobre o assunto revelam que a presença desse tipo de prática musical é uma forma camuflada de a escola exercer seu "poder-pudor". Ou seja, a escola desenvolve mecanismos disfarçados de comando, para manter o controle do tempo e do espaço (MAFFIOLETTI, 2001, p.134)

As atividades com o corpo também não eram recorrentes e durante a observação foi constatado que os alunos brincavam de capoeira, de banda, entre outras nos momentos de brincadeiras livres. Assim, o movimento tornou-se um aspecto fortemente a ser ressaltado. $\mathrm{O}$ RCNEI traz considerações importantes sobre o movimento. Na perspectiva do referencial,

É muito importante que o professor perceba os diversos significados que pode ter a atividade motora para as crianças. Isso poderá contribuir para que ele possa ajudálas a ter uma percepção adequada de seus recursos corporais, de suas possibilidades e limitações sempre em transformação, dando-lhes condições de se expressarem com liberdade e de aperfeiçoarem suas competências motoras.

O professor deve refletir sobre as solicitações corporais das crianças e sua atitude diante das manifestações da motricidade infantil, compreendendo seu caráter lúdico e expressivo. Além de refletir acerca das possibilidades posturais e motoras oferecidas no conjunto das atividades, é interessante planejar situações de trabalho voltadas para aspectos mais específicos do desenvolvimento corporal e motor (BRASIL, 1998, p. 39). 
Também existia certa dificuldade em reconhecer as letras e palavras nos momentos educativos com a chamada, assim o trabalho poderia ser pensado na perspectiva de construção da alfabetização e letramento. Em relação à isto é possível considerar a necessidade de pensar práticas onde as crianças, mesmo pequenas, com média de cinco anos, reflitam sobre a língua oral e escrita, as letras e os sons. Segundo Soares (2003), alfabetização e letramento são processos interdependentes, mesmo que sendo conceitos diferentes. Historicamente foram desenvolvidos separados, quando por muito tempo utilizando métodos tradicionais de alfabetização reforçava-se o uso e ensino das letras e sons e apenas posteriormente discutia-se o aspecto social da alfabetização quando começava o uso social do mesmo através dos diversos gêneros textuais. Enquanto a alfabetização se refere à aquisição do sistema de escrita, o letramento é o uso deste sistema em práticas sociais com a escrita, sendo assim, mesmo sendo processos diferentes com metodologias diferentes, um complementa o outro, e o espaço da Educação Infantil é privilegiado promovendo o desenvolvimento destes aspectos educativos.

Dessa forma, inicialmente, foi definida a temática principal no âmbito da Música. Porém, percebemos que a brincadeira poderia compreender todas as dimensões.

Brincar é uma das atividades fundamentais para o desenvolvimento da identidade e da autonomia. O fato de as crianças, desde muito cedo poder se comunicar por meio de gestos, sons e mais tarde representar determinado papel na brincadeira faz com que ela desenvolva sua imaginação. Nas brincadeiras as crianças podem desenvolver algumas capacidades importantes, tais como a atenção, a imitação, a memória, a imaginação (BRASIL, 1998, p.22).

Desta forma, intitulou-se assim a temática: "Eu brinco, tu brincas, nós brincamos: Quem quer brincar?”. Os subtemas vieram de acordo à atender as especificidades encontradas nos diversos momentos de observação e estruturaram-se da seguinte forma: "Brincando com letras, Brincando com arte, Brincando com números e Brincando com a história”. Os objetivos foram estruturados conforme recomenda o RCNEI, buscando atender as subtemáticas. Assim, esta construção aconteceu da seguinte forma: 
Figura 1 - O caminho de construção das temáticas

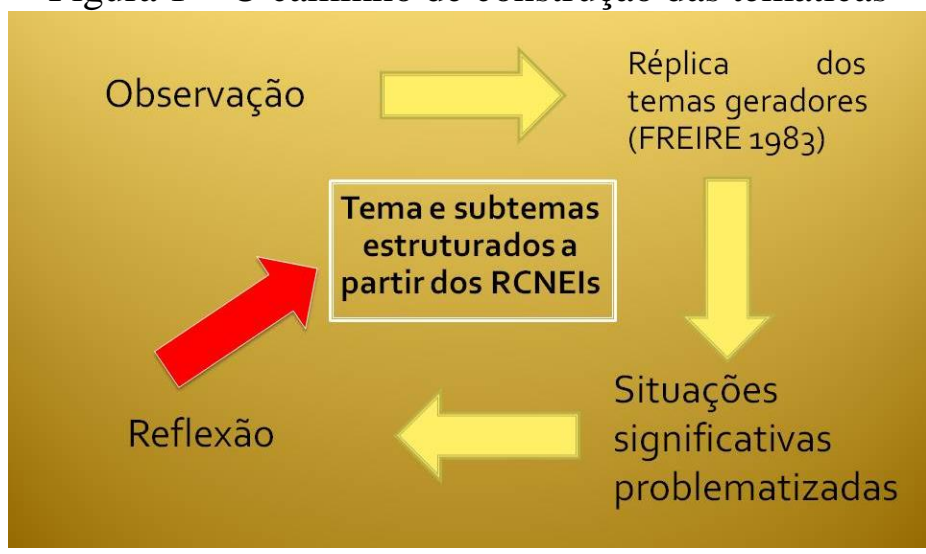

Fonte: Os autores.

As subtemáticas desdobraram-se nas $80 \mathrm{~h}$ de aula. Assim, desenvolveram-se diferentes atividades como: contar histórias; construção de cartazes coletivos; mural com memórias do estágio; práticas músicas onde as crianças cantavam e exploravam o violão levado pelo estagiário no qual cantaram musicas temáticas de histórias e do hino da cidade visto o encontro do aniversário da cidade e a temática do estágio (brincando com a história); fazendo brigadeiros e massa de modelar caseira como prática de artes; diferentes momentos de brincadeiras e leitura a partir do uso da sala de aula e do cantinho da leitura; a chamada, como forma de rotina para refletir sobre a língua escrita e o nome como unidade de significado; brincadeiras matemáticas com músicas, jogos e a sistematização destas brincadeiras; entre tantas outras realizadas.

Assim, numa prática pedagógica progressista (FREIRE, 1999), ensinar significa “inquietar os educandos, desafiando-os ao mundo dado; para que percebem que o mundo dado é um mundo dando-se e que, por isso mesmo, pode ser mudado, transformado, reinventado" (p. 30). Dessa forma, a Educação Infantil mostra-se um espaço privilegiado onde as crianças juntamente com seu professor (a) estarão em constante desvendamento do mundo, criando e reinventando. Assim, "O papel da professora, enquanto participante também, nesta atividade, é o de coordenar a conversa. É o de alguém que, problematizando as questões que surgem, desafio o grupo a crescer na compreensão de seus próprios conflitos (FREIRE, M, 1983, p. 21)".

Assim, em forma de imagem, a construção desdobrou-se da seguinte forma: 
Figura 2: Situações, temática e subtemáticas propostas

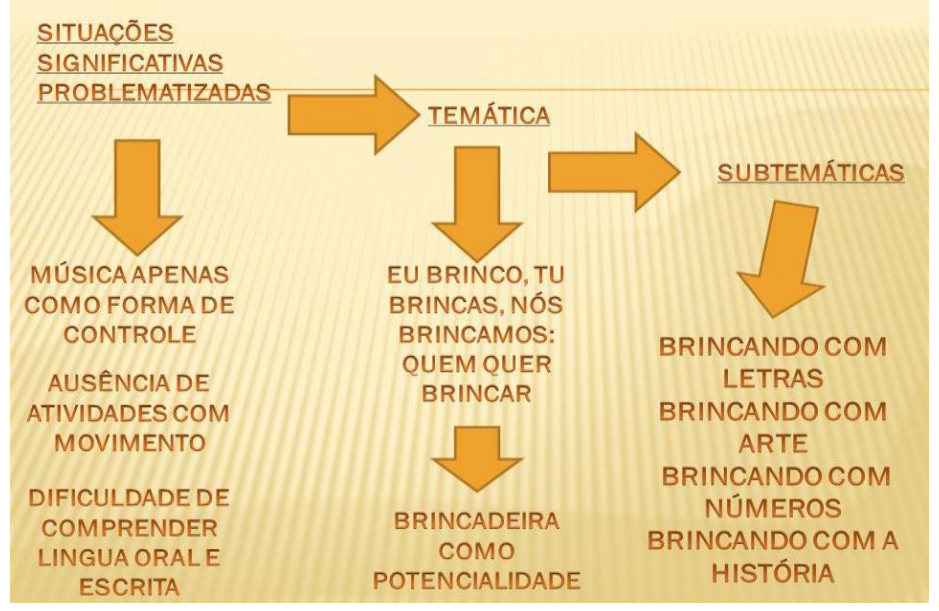

Fonte: Os autores.

\section{Considerações finais}

Através desta reflexão, desde a investigação temática freireana até os desdobramentos possíveis na construção de temáticas de trabalho para a Educação Infantil é possível olhar para a aula e, através dela, das práticas educativas e das relações estabelecidas construir indicativos para criar, inventar e inovar, sem medo de ousar.

Assim, é possível afirmar a necessidade da observação e da construção de temáticas significativas na docência na Educação Infantil. Sem dúvida, hoje urge a necessidade de uma educação cada vez mais problematizadora e mais voltada para a realidade. Assim, pensar esta educação exige olhar para ela com olhar diferenciado, como escreve Arendt (2014),

A educação é, também, onde decidimos se amamos nossas crianças o bastante para não expulsá-las do nosso mundo e abandoná-las a seus próprios recursos, e tampouco arrancar de suas mãos a oportunidade de empreender alguma coisa nova e imprevista para nós, preparando-as em vez disso com antecedência para a tarefa de renovar um mundo comum (ARENDT, 2014, p.247).

\section{Referências}

ANDREOLA, Balduíno A. O processo de conhecimento em Paulo Freire. Educação e Realidade, Porto Alegre, v18, n.1, p.32-42, jan./jun. 1993.

ARENDT, Hannah. Entre o passado e o futuro. São Paulo: Perspectiva, 2014.

BARREIRO, Iraíde Marques de Freitas; GEBRAN, Raimunda Abou. Prática de ensino: elemento articulador da formação do professor. IN: BARREIRO, Iraíde Marques de Freitas; GEBRAN, Raimunda Abou. Prática de ensino e estágio supervisionado na formação de professores. São Paulo: Avercamp, 2006. 
BRASIL. Referencial curricular nacional para a educação infantil. Ministério da Educação e do Desporto, Secretaria de Educação Fundamental. — Brasília: MEC/SEF, 1998. Ministério da Educação. Ministério da Educação. Conselho Nacional de Educação. Resolução CEB n. 05, 17 dez. 2009. Institui as Diretrizes Curriculares Nacionais para a Educação Infantil. Diário Oficial República Federativa do Brasil, Brasília, DF, 18 dez. 2009. Seção 1, p. 18.

CHARLOT, B. Da relação com o saber: Elementos para uma teoria. Porto Alegre: Artmed, 2000.

DELIZOICOV; ANGOTTI. Metodologia do Ensino de Ciências. São Paulo: Cortez, 1994.

ESTRELA, Albano. Pedagogia, ciência da educação? Porto, Editora Porto, 1992.

FREIRE, Paulo. Pedagogia do Oprimido. Paz e Terra: Rio de Janeiro, 1983. Terra, 1996.

Pedagogia da autonomia: saberes necessários à prática educativa. São Paulo: Paz e , Paulo. A educação na cidade. 3. ed. São Paulo: Cortez, 1999.

Criando métodos de pesquisa alternativa: aprendendo a fazê-la melhor através da ação. In: BRANDÃO, C. R (org). Pesquisa participante. São Paulo: Brasiliense, 2006.

FREIRE, Madalena. A paixão de conhecer o mundo: relato de uma professora. Rio de Janeiro: Paz e Terra, 1983.

MAFFIOLETTI, Leda de Albuquerque. Práticas Musicais na Escola Infantil. In: CRAIDY, Maria; KAERCHER, Gládis Elise P. da Silva (orgs.) Educação infantil: pra que te quero? Porto Alegre: Artmed, 2001.

PIMENTA, Selma Garrido; LIMA, Maria Socorro Lucena. Estágio e Docência. São Paulo: Cortez, 2004.

PORLÁN, Rafael; MARTIN, José. El diário del professor: um recurso para la investigación en el aula. Sevilla: Díada, 1997.

SOARES, Magda. Letramento e alfabetização: as muitas facetas. CD-ROMda $26^{\circ}$ Reunião Anual da ANPED. Caxambu. Versão on-line disponível no site www.anped.org.br/26ra.htm. GT 10 - Alfabetização, leitura e escrita, 2003.

ZABALZA, Miguel. Diários de aula: um instrumento de pesquisa e desenvolvimento profissional. Porto Alegre: Artmed, 2004. 